\title{
8. THE ROLE OF ARCTIC SEA ICE AND SEA SURFACE TEMPERATURES ON THE COLD 2015 FEBRUARY OVER NORTH AMERICA
}

\author{
Omar Bellprat, François Massonnet, Javier García-Serrano, Neven S. Fučkar, Virginie Guemas, \\ and Francisco J. Doblas-ReYES
}

\begin{abstract}
The cold spell of February 2015 in North America was predominantly internally generated; reduced Arctic sea ice and anomalous sea surface temperatures may have contributed in establishing and sustaining the anomalous flow.
\end{abstract}

Introduction. North America (NA) has experienced a series of cold winters in the last decade that have repeatedly broken records (van Oldenborgh et al. 2015; Hartmann 2015). The winter of $2014 / 15$ was no exception. Montreal recorded the coldest February ever observed and the eastern North American region (ENA; land points only, black box in Fig. 8.1a) experienced the second coldest month since 1900 (see Supplemental Fig. S8.1). The severe February anomaly was accompanied with several intense snowstorms leading to power outages and associated large economic losses (Munich Re, press release, 4 January 2016). The record is surprising given that the region has experienced a $1.4^{\circ} \mathrm{C}$ warming since 1900, compatible with global warming (Tebaldi et al. 2013). Taking this warming into account (following van Oldenborgh et al. 2015), the return period of such an extreme cold event in 2015 is approximately 1000 years, while in 1900 the same event would have occurred on average every 100 years.

Low temperatures over the Northeast in winter are generally associated with pronounced and stationary meandering of the jet stream that channels cold Arctic air into lower latitudes (Diaz and Quayle 1978).

AfFiliations: Bellprat, García-Serrano, FučKarEarth Sciences Dept., Barcelona Supercomputing Centre, Barcelona, Spain; MASSONNET-Earth Sciences Dept., Barcelona Supercomputing Centre, Barcelona, Spain, and Georges Lemaître Center for Earth and Climate Research, Earth and Life Institute, Université catholique de Louvain, Louvain-la-Neuve, Belgium; Guemas-Earth Sciences Dept., Barcelona Supercomputing Centre, Barcelona, Spain, and Centre National de Recherches Météorologiques, Météo-France, Toulouse, France; DoBLASREYES-Earth Sciences Dept., Barcelona Supercomputing Centre, and Institució Catalana de Recerca i Estudis Avançats, Barcelona, Spain

DOI:10.1175/BAMS-D-16-0159.I

A supplement to this article is available online (10.II75 /BAMS-D-I6-0159.2)
Although the winter yielded a persistent, strong positive North Atlantic Oscillation (NAO) ${ }^{1}$, a wavy structure over NA prevailed in February 2015 as shown in Fig. $8.1 \mathrm{~b}$ for the geopotential height at $500 \mathrm{hPa}$. The anomaly started to develop in the troposphere in January but intensified and became more meridional in February, concomitant with a strengthening of the polar vortex (Supplemental Fig. S8.2). We investigate in this article the potential drivers of both the surface cold anomaly and the anomalous meander of the jet stream in 2015 using an index which measures the meridional wind component at $500 \mathrm{hPa}$ averaged over central North America (CAN; black box in Fig. 8.1b and time-series Supplemental Fig. S8.1).

Although these atmospheric conditions may be part of the natural atmospheric variability, their recurrence during the last decade is striking (Francis and Vavrus 2012), and recent studies have proposed mechanisms to explain its prevalence. The most debated cause points toward the Arctic amplification and the associated accelerated Arctic sea ice retreat (Overland et al. 2015). Reduced sea ice concentration (SIC) leads to strong heat release from the ocean that could modify the meridional temperature gradient and, thus, alter the jet stream and sea level pressure patterns at midlatitudes (e.g., Cohen et al. 2014). A direct, local atmospheric response to the Arctic surface warming could also force anticyclonic circulation anomalies at the surface and project onto a wave-like structure at mid-upper-tropospheric levels (Kug et al. 2015). February 2015 Arctic sea ice conditions depicted in Fig. 8.1c show the third lowest extent since 1979.

A significant body of literature questions this relationship and argues that recent cold winter can

${ }_{1}$ The monthly NAO index based on Z500 reached 1.86, 1.79, and 1.32 in December, January, and February, respectively (Source: NOAA/CPC). 
(a)
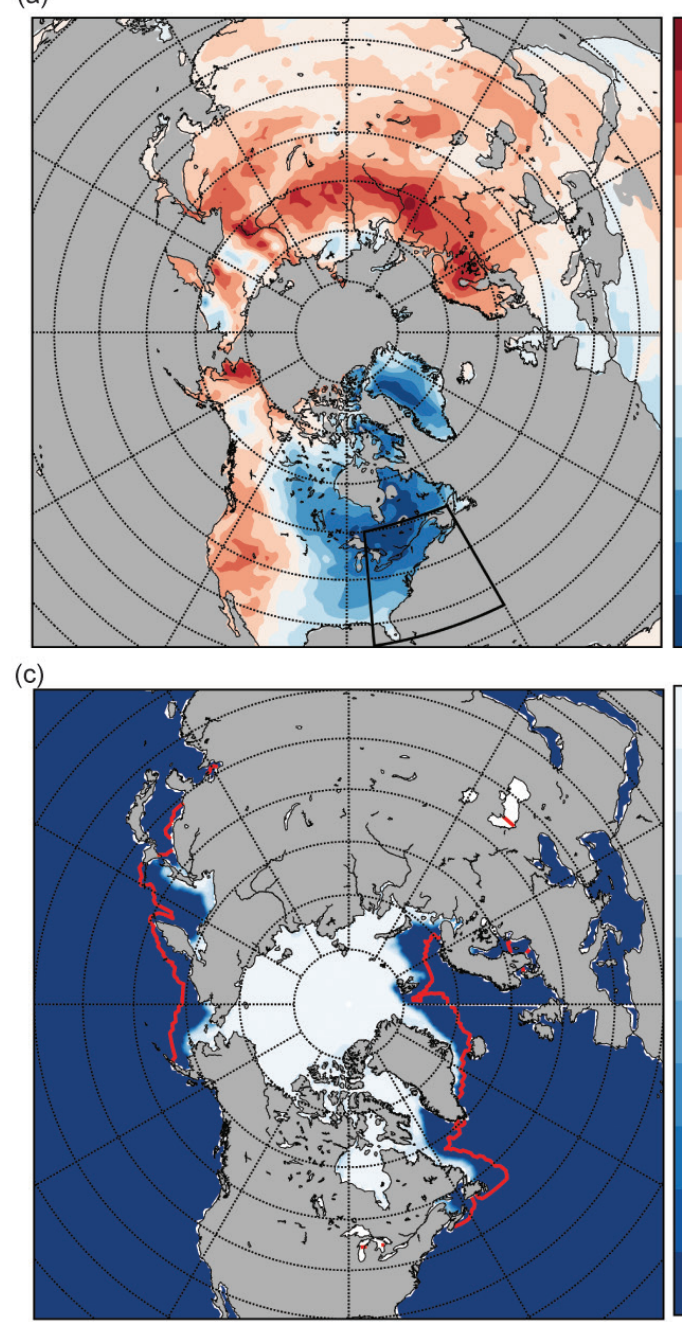

(e)

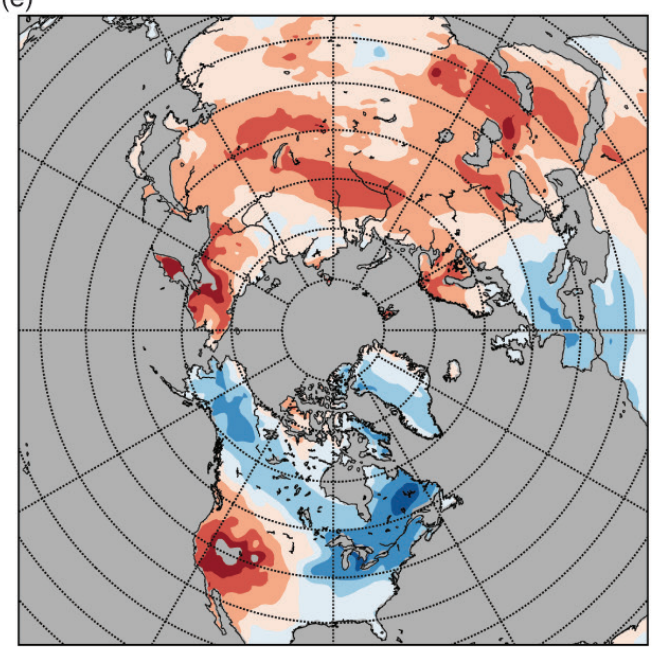

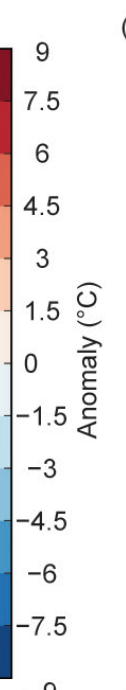

$-9 \quad(d)$

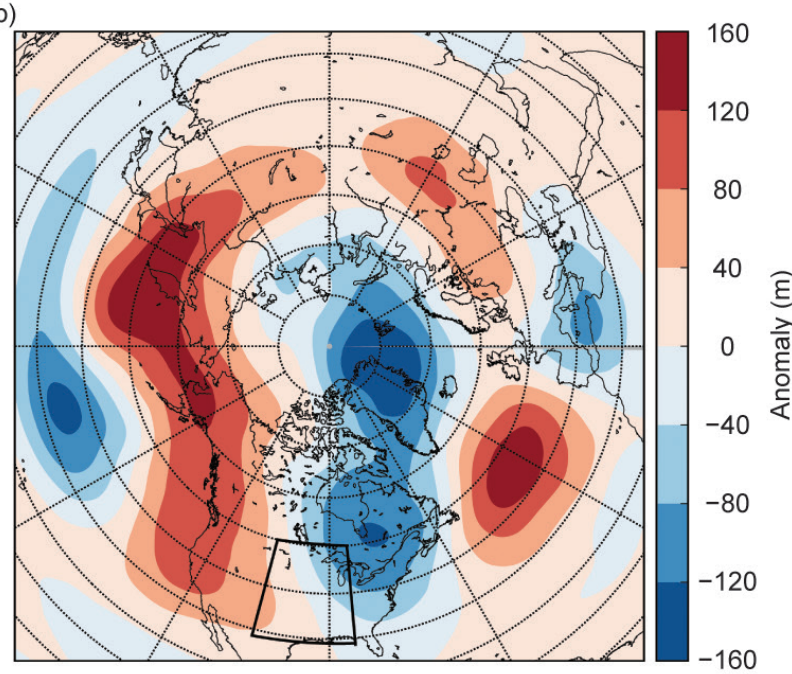

(d)

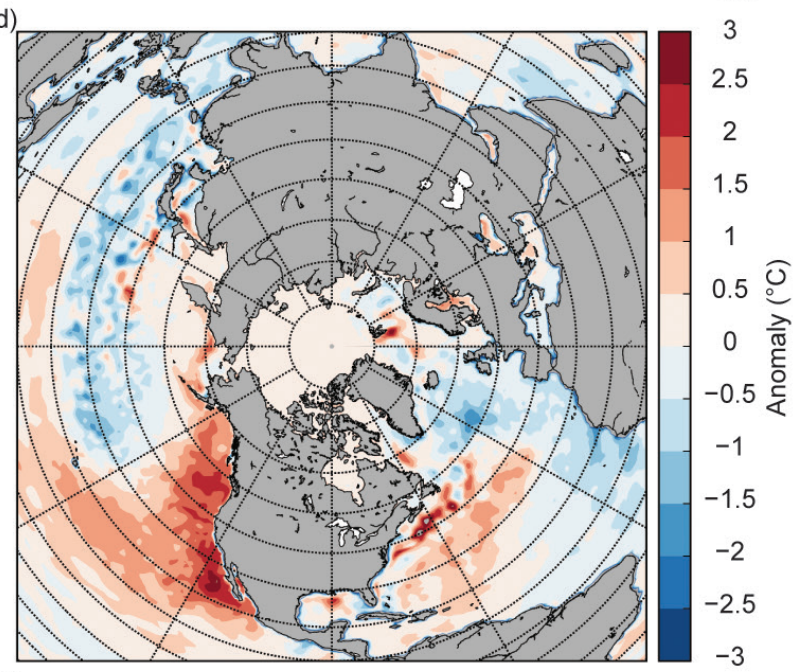

(f)

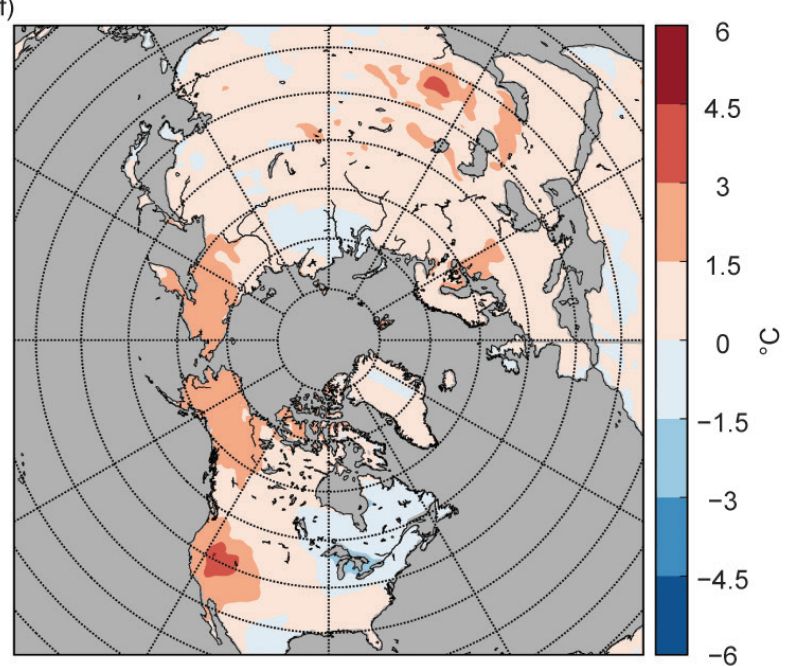

FIG. 8.I. The cold Feb 2015 as observed in the ERA-Interim reanalysis (a)-(d) and simulated 2-m temperature with the atmosphere-only IFS model. (c) The red line shows the SIC climatology (198I-2000) while all other panels show the anomaly from the climatology 198I-2010. Model predictions show the ensemble mean of 100 members starting on (e) I Feb and (f) I Jan. The amplitude of the model predictions is scaled to a smaller range than for the observations. (a) The black box denotes the ENA region and (b) the CAN region used to define the event. 
not be understood by Arctic sea ice decline (e.g., Barnes 2013) and find that these are an articulation of internal atmospheric variability (Sun et al. 2016). Hartmann (2015) relates the recent series of cold NA events to an oceanic internal anomaly of sea surface temperature (SST) prevailing over the east Pacific in 2015, and referred to as the North Pacific mode (NPM; Deser and Blackmon 1995). However, the NPM decayed to an almost neutral state at the beginning of 2015 (Supplemental Fig. S8.3), although a confined positive anomaly along the west coast of NA markedly remained (Fig. 8.1d and globally Supplemental Fig. S8.4).

Reforecasting the cold February 2015. The aim of this study is to assess, using retrospective climate predictions, the contributions of the described anomalous SST pattern (of predominantly natural origin; Hartman 2015) and Arctic sea ice retreat (mainly attributable to anthropogenic climate change; Bindoff 2013) to the occurrence of the cold NA and its associated flow. The predictions rely on simulations using the atmosphere-only integrated forecast system (IFS; cycle 36r4) forced by SST and SIC from the ERAInterim reanalysis (Dee et al. 2011). Three types of retrospective predictions of February 2015 are carried out. A first experiment aims at reproducing the event using actual atmospheric conditions in 2015 as initial conditions and surface boundary forcings (hereafter referred to as INI). Two additional experiments test the sensitivity to either SST (using a 1981-2010 SST climatology instead of the 2015 state as boundary conditions, CLIMSST) or SIC (using a 1981-2000 SIC climatology, hereafter CLIMICE, omitting the last decade in order to exclude Arctic sea ice decline in the climatology). Note that prescribing SSTs bears the risk of exaggerated ocean heat release due to the lack of coupling with the ocean and thus potentially overestimates the influence of anomalous SSTs.

Each experiment is initialized from observational estimates of the atmospheric state from ERA-Interim including singular vector perturbations (Buizza and Palmer 1994) to generate 100 ensemble members. The experiments are initialized on 1 January and 1 February to assess timescales at which predictability of the event emerges. Furthermore, a hindcast set of the 1981-2010 period has been carried out using three-monthly predictions initialized each 1 January and 1 February with ten ensemble members in order to evaluate the reliability of the model to simulate cold events over North America and identify systematic biases in the mean for bias correction.
The ensemble-mean prediction starting in February (Fig. 8.1e) captures the event shown with a pronounced cold anomaly in the Northeast and a warming in the Southwest. Both experiments using either climatological SSTs or climatological SIC reproduce the event as well, demonstrating that the atmospheric initial state holds the main sources of predictability of the event. The ensemble-mean prediction starting in January (Fig. 8.1f) shows much less pronounced temperature anomalies over the target region and does not reproduce the spatial pattern. This suggests that surface boundary conditions did not force the core of the event, neither did potential stratospheric precursors (Supplemental Fig. S8.5) or anomalies linked to sea ice conditions preceding the predictions (Kim et al. 2014).

Attribution to surface boundary conditions. Retrospective predictions of the extreme cold February 2015 suggest that the atmospheric flow established in late Januaryearly February was mainly internally generated, yet surface boundary conditions could still have played a role in altering the probability that such an unlikely event occurred. To answer this question, we compare the probabilities to observe the recorded temperatures anomalies and their associated anomalous flow in the CLIMSST, CLIMICE, and INI experiments. The attribution relying on predictions starting in January and February is seemingly similar, but addresses a different question since the atmospheric anomaly is largely set in on 1 February. The attribution relying on the February and January predictions therefore quantifies how surface boundary conditions have contributed in sustaining or establishing the anomaly, respectively. The model ensembles are calibrated following Bellprat and Doblas-Reyes (2016), in order to correct for model limitations in representing this type of events (more details in the online supplemental material).

The calibrated probability density functions (PDFs) of the 100 members of the model ensembles are shown in Figs. 8.2a,b (temperature) and Figs. $8.2 \mathrm{e}, \mathrm{f}$ (jet). The predictions starting in February are shifted towards the observed anomalies (black lines) while the predictions starting in January have almost no ensemble-mean anomaly as discussed in the previous section. The picture is overall consistent between temperature and the jet index. Changes in the surface boundary forcing reduce the ensemble variability in all cases, yet only significantly for the jet index (F-test at $5 \%$ significance level). The ensemblemean is slightly colder in CLIMSST, possibly linked to 
(a)

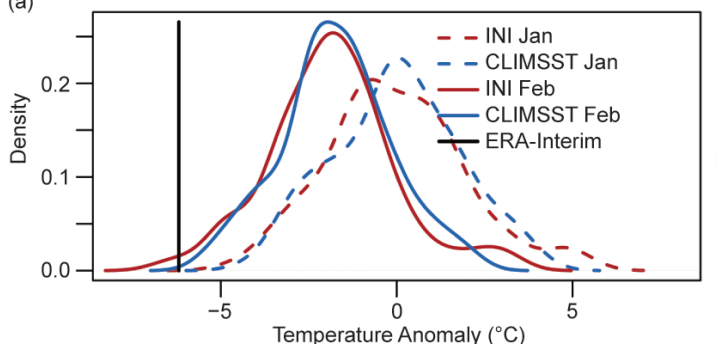

(c)

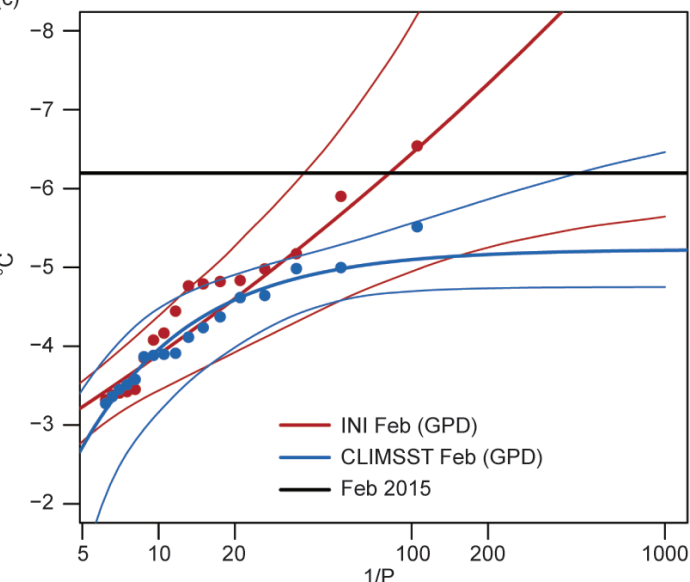

(e)

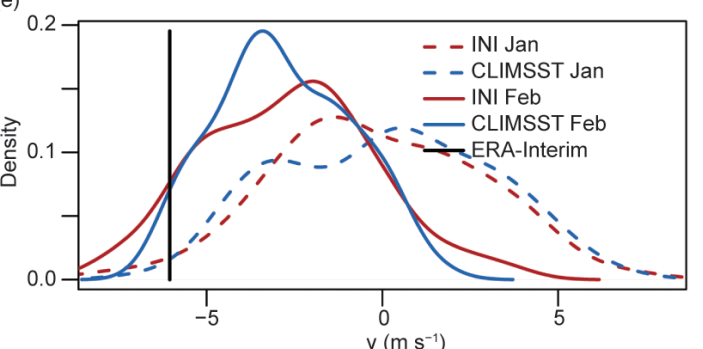

(g)

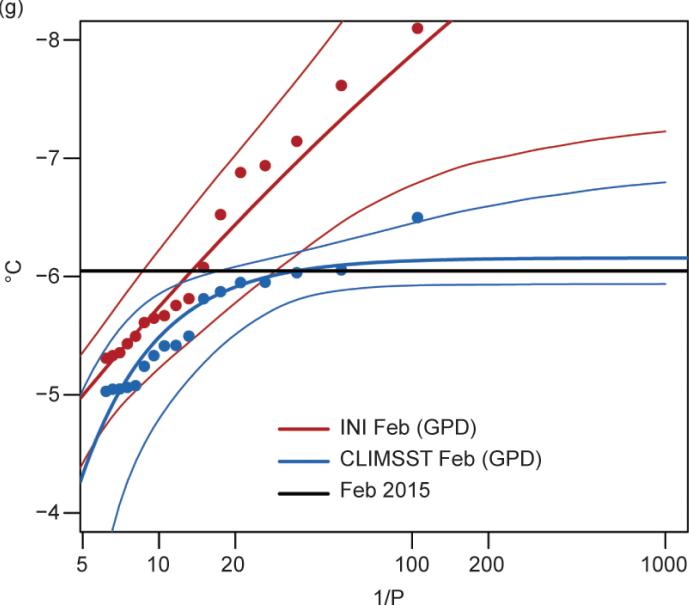

(b)
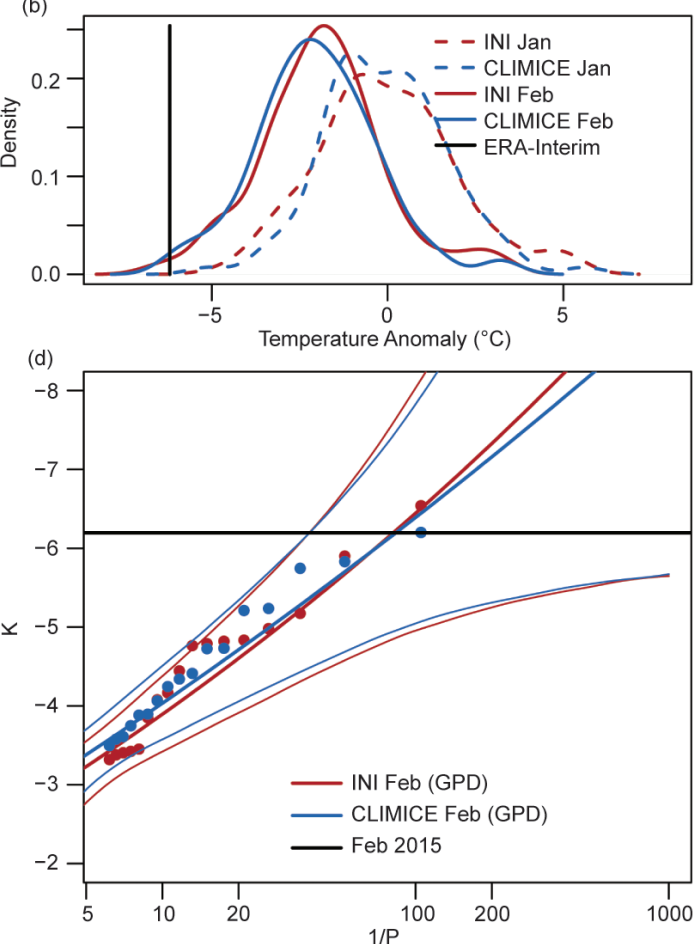

(f)
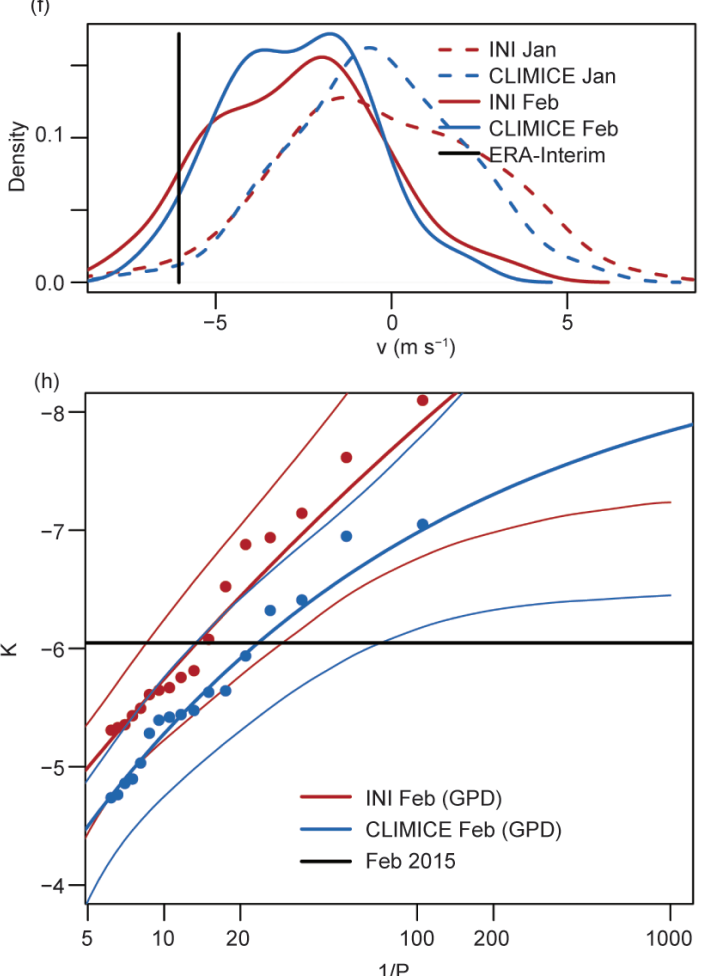

Fig. 8.2. (a)-(d) Simulated Feb 2015 2-m temperature anomalies $\left({ }^{\circ} \mathrm{C}\right)$ and $(\mathrm{e})-(\mathrm{h})$ anomalies of the jet index $\left(\mathrm{m} \mathrm{s}^{-1}\right)$ with respect to the model climatology when starting the predictions in Jan (dashed) and in Feb (continuous). (a),(b) and (e),(f) compare the PDFs of the simulations with observed conditions of SST and SIC to the one using climatological conditions CLIMSST (a),(e) and CLIMICE (b),(f) using kernel smoothed densities. The black line denotes the observed anomaly. (c),(d) and (g),(h) show a peak over threshold analysis of the ensemble tails comprising of a GPD for the Feb predictions. The lines show the central estimate with the 5\%-95\% confidence interval obtained by resampling the ensemble data with replacement. 
advection of colder Arctic temperatures (compared to INI) due to larger ice coverage (Sun et al. 2016). The observed event represents a rare case, particularly for the temperature anomaly, and a generalized Pareto distribution (GPD) retaining 20\% of ensemble data is used to estimate the event probability for predictions starting in February (Figs. 8.2c,d and g,h) and January (Supplemental Fig. S8.4). The return period of the temperature anomaly in the conditioned predictions (starting in February) is 100 years and around 1000 years in the unconditioned predictions (starting in January), consistent with the return time estimated from the observations as described in the introduction.

Changes in event probabilities (intercept with the black line, Fig. 8.2) reveal lower probabilities in CLIMSST for both temperature and the jet index and lower probabilities for CLIMICE for the jet index compared to INI. For the temperature anomaly, sea ice conditions seem not to have played a role. The uncertainty ranges (determined by resampling) are overall large (95\% confidence bounds, thin lines). Differences in probabilities are qualitatively consistent with predictions starting in January. Overall we find that SST and SIC have increased the probability of establishing a meandering flow approximately by a factor 10 (January predictions, Supplemental Figs. S8.4e,f) and doubled the probability that the flow maintained its wavy structure (February predictions, Figs. $8.2 \mathrm{~g}, \mathrm{~h}$ ). The temperature anomaly would have been extremely unlikely if anomalous SSTs would not have persisted in February (Fig. 8.2c), yet the cold anomaly represents an extreme case without preconditioning the flow (Supplemental Figs. S8.4ad), regardless of the surface boundary forcing.

As a summary we conclude that reduced Arctic sea ice, which is linked to anthropogenic activity, and anomalous SSTs, mainly a consequence of natural variability, did not drive the core of the event, but they may have both contributed in establishing and sustaining the anomalous meander of the jet stream, and hence, could contribute in the near future to enlarge the probability of such extreme cold spells in the region.

ACKNOWLEDGEMENTS. This work was funded by the EU projects EUCLEIA (607085), SPECS (308378), and PRIMAVERA (641727). The authors are supported by the following fellowships: Bellprat (ESA Living planet, VERITAS-CCI), Massonnet and Fučkar (Juan de la Cierva), García-Serrano (Marie Currie, DPETNA, 655339), Guemas (Ramón y Cajal)
The author thankfully acknowledges the computer resources, technical expertise, and assistance provided by the Red Española de Supercomputación. We further thank constructive comments from Martin Hoerling and three anonymous reviewers.

\section{REFERENCES}

Barnes, E. A., 2013: Revisiting the evidence linking Arctic amplification to extreme weather in midlatitudes. Geophys. Res. Lett., 40, 4734-4739, doi:10.1002/grl.50880.

Bellprat, O., and F. Doblas-Reyes, 2016: Attribution of extreme weather and climate events overestimated by unreliable climate simulations. Geophys. Res. Lett., 43, 2158-2164, doi:10.1002/2015GL067189.

Bindoff, N. L., and Coauthors, 2013: Detection and attribution of climate change: from global to regional. Climate Change 2013: The Physical Science Basis, T. Stocker et al., Eds., Cambridge University Press, 867-952.

Buizza, R., and T. N. Palmer, 1995: The singular-vector structure of the atmospheric global circulation. J. Atmos. Sci., 52, 1434-1456.

Cohen, J., J. A. Screen, J. C. Furtado, M. Barlow, D. Whittleston, D. Coumou, and J. Jones, 2014: Recent Arctic amplification and extreme mid-latitude weather. Nat. Geosci., 7, 627-637, doi:10.1038 /ngeo2234.

Dee, D. P., and Coauthors, 2011: The ERA-Interim reanalysis: Configuration and performance of the data assimilation system. Quart. J. Roy. Meteor. Soc., 137, 553-597.

Deser, C., and M. L. Blackmon, 1995: On the relationship between tropical and North Pacific sea-surface temperature variations. J. Climate, 8, 1677-1680.

Diaz, H. F., and R. G. Quayle, 1978: The 1976-77 winter in the contiguous United States in comparison with past records. Mon. Wea. Rev., 106, 1393-1421.

Francis, J. A., and S. J. Vavrus, 2012: Evidence linking Arctic amplification to extreme weather in mid-latitudes. Geophys. Res. Lett., 39, L06801, doi:10.1029/2012GL051000.

Hartmann, D. L., 2015: Pacific sea surface temperature and the winter of 2014. Geophys. Res. Lett., 42, 18941902, doi:10.1002/2015GL063083.

Kim, B.-M., S.-W. Son, S.-K. Min, J.-H. Jeong, S.-J. Kim, X. Zhang, and J.-H. Yoon, 2014: Weakening of the stratospheric polar vortex by Arctic sea-ice loss. Nat. Comm., 5, 4646, doi:10.1038/ncomms5646. 
Kug, J.-S., J.-H. Jeong, Y.-S. Jang, B.-M. Kim, C. K. Folland, S.-K. Min, and S.-W. Son, 2015: Two distinct influences of Arctic warming on cold winters over North America and East Asia. Nat. Geosci., 8, 759762, doi:10.1038/ngeo2517.

NOAA/CPC (National Weather Service, Climate Prediction Center), cited 2016: Monthly mean NAO index since January 1950. [Available online at www .cpc.ncep.noaa.gov/products/precip/CWlink/pna /nao.shtml.]

Overland, J., J. A. Francis, R. Hall, E. Hanna, S.J. Kim, and T. Vihma, 2015: The melting Arctic and midlatitude weather patterns: Are they connected? J. Climate, 28, 7917-7932, doi:10.1175 /JCLI-D-14-00822.1.

Sun, L., J. Perlwitz, and M. Hoerling, 2016: What caused the recent "Warm Arctic, Cold Continents" trend pattern in winter temperatures? Geophys. Res. Lett., 43, 5345-5352, doi:10.1002/2016GL069024.

Tebaldi, C., D. Adams-Smith, and A. Kenward, 2013: Warming winters U.S. temperature trends. Climate Central Special Report, 15 pp. [Available online at www.climatecentral.org/wgts/warming-winters /WarmingWinters.pdf.]

van Oldenborgh, G. J., R. Haarsma, H. De Vries, and M. R. Allen, 2015: Cold extremes in North America vs. mild weather in Europe: The winter of 2013-14 in the context of a warming world. Bull. Amer. Meteor. Soc., 96, 707-714, doi:10.1175/BAMS-D-14-00036.1. 